\title{
Endocytosis in the retinal and choroidal microcirculation
}

\author{
T A GARDINER AND D B ARCHER
}

From the Department of Ophthalmology, The Queen's University, Belfast, Eye and Ear Clinic, Royal Victoria Hospital, Belfast

SUMmaRY The endocytosis of horseradish peroxidase (HRP) by the vascular cells of retinal and choroidal blood vessels was compared in immersion and perfusion fixed eyes from individual rats. The mechanisms of endocytosis of HRP appeared identical in both retinal and choroidal vessels. The bulk of internalised tracer occurred in macropinosomes $300-400 \mathrm{~nm}$ in diameter. Tracer was localised to a 20-30 $\mathrm{nm}$ layer on the internal aspect of the limiting membrane. This layer was coincident with the glycocalyx of the luminal plasma membrane as revealed by ruthenium redosmium tetroxide staining. Horseradish peroxidase was also internalised by a small scattered population of vesicles $(100-130 \mathrm{~nm}$ in diameter). The size of these vesicles suggested that they may have arisen from clathrin coated regions of the plasma membrane. It is suggested that the endocytosis of HRP in retinal and choroidal vascular endothelium occurs as a function of plasma membrane recycling. Horseradish peroxidase may also be internalised as a 'contaminant' of the glycocalyx in coated pits involved in receptor mediated endocytosis. The smooth $80 \mathrm{~nm}$ plasmalemmal caveolae of the retinal and choroidal vascular endothelial cells did not appear to participate either in absorptive endocytosis or vesicular transport.

The retinal blood vessels are lined by a continuous non-fenestrated endothelium, the individual cells of which are joined by tight junctions. This layer of cells forms a highly selective barrier between the circulation and the extracellular space of the retinal neuropile, insulating the sensitive central nervous system neurones from the chemical milieu of the blood stream. The retinal vascular endothelium with its tight junctions has been termed the inner blood retinal barrier.'

The permeability characteristics of the choroid are largely determined by the abundantly fenestrated choriocapillaris. Several ultrastructural studies have shown the choriocapillaris to be freely permeable to horseradish peroxidase ${ }^{1-3}$ and ferritin, though the basement membrane provides some impediment to the latter. ${ }^{4}$ The outer retina is separated from this highly permeable capillary network by the retinal pigment epithelial cells, which are linked by encircling tight junctions.

The eye therefore provides unique opportunities

Correspondence to T A Gardiner, Department of Ophthalmology, The Queen's University of Belfast, Eye and Ear Clinic, Royal Victoria Hospital, Belfast BT12 6BA, Northern Ireland. for direct comparison of a 'barrier' circulation (retinal) with a highly permeable visceral type of circulation (choroidal) under identical experimental conditions. The fate of horseradish peroxidase was studied in the retinal and choroidal microvasculatures of individual animals after both immersion and perfusion fixation.

\section{Materials and methods}

All procedures on living animals were carried out under deep pentobarbital anaesthesia. Four rats were injected with horseradish peroxidase (Sigma Type VI, $20 \mathrm{mg} / 100 \mathrm{~g}$ body weight in normal saline via the femoral vein), which was allowed to circulate for 15 minutes before enucleation of the left eye and perfusion fixation of the right. The distribution of peroxidase reaction product was compared in immersion and perfusion fixed retina and the adherent choroid of the same tissue slices. As controls two non-injected siblings were fixed by vascular perfusion and slices of retina and choroid incubated for endogenous peroxidase activity.

Immersion fixation of tissues under study was 
carried out in $2.5 \%$ glutaraldehyde in $0.1 \mathrm{M}$ cacodylate buffer ( $\mathrm{pH} 7.4$ ) containing $0.025 \%$ magnesium chloride for three hours. Perfusion fixation was accomplished via the ascending aorta with a simple gravity-feed apparatus. A 6-foot $(180 \mathrm{~cm})$, head of fluid has been recommended for perfusion fixation of neural tissues in rats, cats, and monkeys. ${ }^{5}$ However, the resultant intravascular pressure in the eye produced some tearing of the intima in the choroidal arteries. A pressure head of 4 feet $(120 \mathrm{~cm})$ was found to give equally good fixation free of discernible artefact. A $2 \cdot 5 \%$ solution of glutaraldehyde in $0.1 \mathrm{M}$ phosphate buffer ( $\mathrm{pH} 7.4$ ) was used for perfusion fixation. A 10-second prewash of phosphate buffered saline was given prior to infusion with fixative. Perfusion fixation was continued for $\mathbf{3 0}$ minutes in situ followed by a 2-hour immersion in fixative (above). Post-fixation was carried out in $1 \%$ osmium tetroxide for 2 hours at $4^{\circ} \mathrm{C}$. For cytochemical demonstration of horseradish peroxidase $100 \mu \mathrm{m}$ tissue-chopped sections were presoaked for 3 hours at $4^{\circ} \mathrm{C}$ in a mixture containing $10 \mathrm{mg}$ diaminobenzidine tetrahydrochloride (DAB) in a $0 \cdot 1 \mathrm{M}$ cacodylate buffer $\mathrm{pH} 7.4$ followed by a 3-hour incubation at room temperature in the same solution at $\mathrm{pH} 5 \cdot 1 \mathrm{(pH}$ optimum of horseradish peroxidase $)^{6}$ with the addition of $0.1 \mathrm{ml}$ of $1 \%$ hydrogen peroxide per $10 \mathrm{ml}$. Osmication was as described above.

To demonstrate the luminal cell coat or glycocalyx of the retinal vascular endothelium the eyes of four additional rats were fixed by vascular perfusion with $2.5 \%$ glutaraldehyde in a $0.1 \mathrm{M}$ cacodylate buffer (pH $7 \cdot 2$ ) containing $0.5 \%$ ruthenium red. Fixation was continued for 15 minutes in situ followed by immersion for a further 45 minutes in the same fixative. The retinae were dissected and small tissue blocks cut into thin slices. All tissue slices were given three 10 -minute washes in $0 \cdot 1 \mathrm{M}$ cacodylate buffer containing $0.5 \%$ ruthenium red prior to staining in ruthenium red/osmium tetroxide after the method of Luft. $^{?}$

All tissue samples were dehydrated with ethanol and embedded in TAAB resin. Thin sections were cut on a Reichert OMU4 ultramicrotome, stained with lead citrate, and photographed on either an AEI Corinth 500 or Philips 301 electron microscope.

\section{Results}

ENDOCYTOSIS OF HORSERADISH PEROXIDASE BY THE VASCULAR CELLS OF THE CHOROID

Electron micrographs of immersion fixed specimens showed that after 15 minutes' exposure to horseradish peroxidase the protein had filled the entire extravascular space of the choroid, outlining cell bodies and connective tissue fibres as negative images within the blackened extracellular matrix. In the choroidal arteries the tracer had outlined large arrays of $80 \mathrm{~nm}$ plasmalemmal caveolae on both the luminal and abluminal plasma membranes of the endothelial cells (Fig. 1). Closely associated with the caveolae were many presumptive micropinocytotic vesicles showing apparent internalisation of peroxidase (Fig. 1). The endothelial cells in these vessels were joined by occluding junctions which proved 'tight' to peroxidase (Fig. 1). Plasmalemmal caveolae and
Fig. 1 Choroidal artery (rat): immersion fixation. Horseradish peroxidase reaction product fills the plasmalemmal caveolae (white arrows) and associated vesicles of the luminal and abluminal plasma membranes of the endothelial cells (E) and the sarcolemmal caveolae (white arrows) of the smooth muscle cells (SM). The intercellular clefts of the endothelium and caveolae of the lateral plasma membranes (black arrow) remain free of peroxidase reaction product. Lumen (L), internal elastic lamina (EL). $(\times 25000)$.

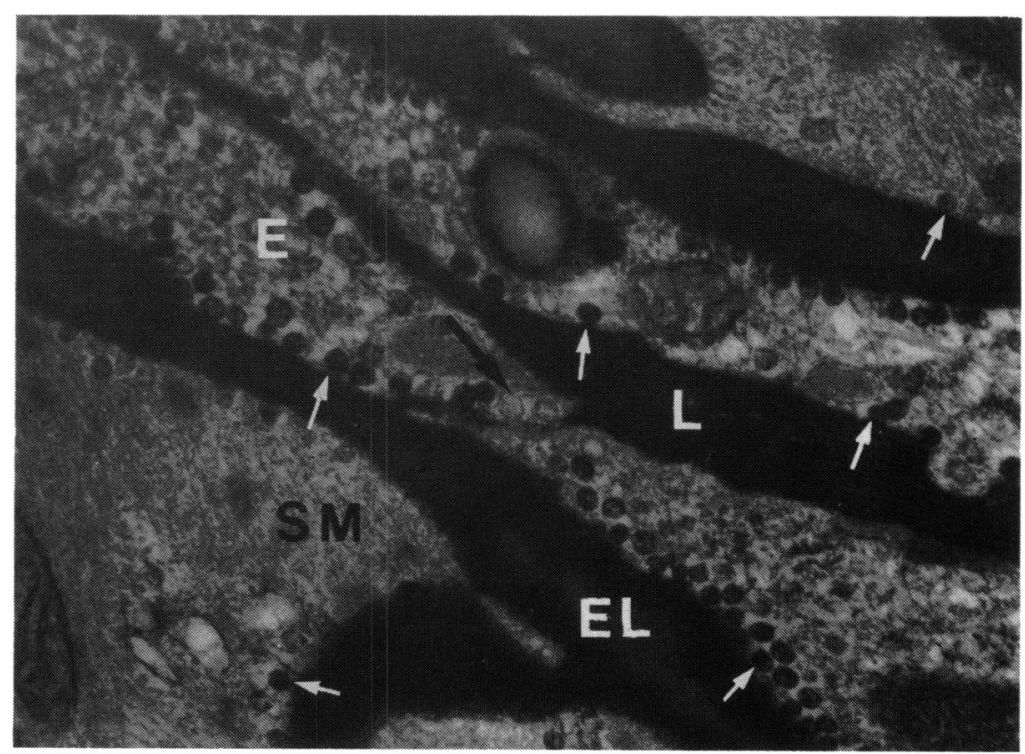




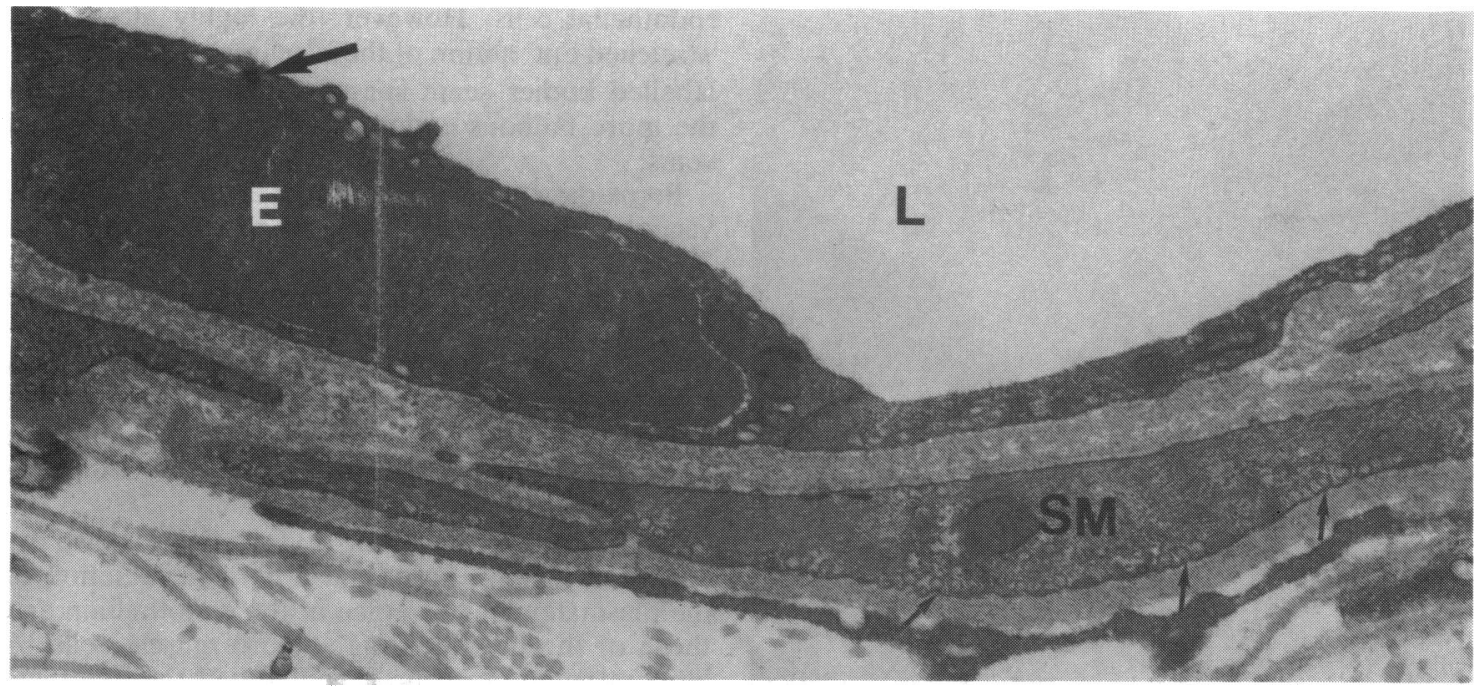

Fig. 2 Choroidal artery (rat):perfusion fixation. The plasmalemmal caveolae and vesicles of the endothelium (E) are largely free of peroxidase. Only a solitary luminal vesicle shows true internalisation (large arrow). The sarcolemmal caveolae of the adjacent smooth muscle cells (SM) are empty (small arrows) and the cells show no evidence of endocytosis. Lumen (L). $(\times 16000)$.

associated vesicles of the lateral plasma membranes lying within the 'protected' intercellular clefts (bounded by tight junctions) remained free of peroxidase (Fig. 1). The sarcolemmal caveolae of the arterial smooth muscle cells stained uniformly with peroxidase. The plasmalemmal caveolae and associated vesicles in the endothelial cells of the choroidal veins and capillaries also stained consistently with peroxidase.

Perfusion fixed choroid bore little resemblance to the immersion fixed material already described. Although the prewash was brief (10 seconds) it was sufficient to purge the extracellular space of peroxidase. The endothelial cells of the arteries stili displayed large numbers of plasmalemmal caveolae and vesicles; however, the vast majority of these were now empty (Fig. 2). Truly internalised enzyme was present in only a small scattered population of vesicles $(100-130 \mathrm{~nm})$, some large endocytic vacuoles (300-400 nm), multivesicular bodies, and dense, presumably heterophagic, vacuoles. (Peroxidase labelled endocytic vacuoles and multivesicular bodies were more common in choroidal veins and venules and will be illustrated in relation to those vessels.)

Peroxidase labelled endocytic vacuoles were more common in the choroidal veins and venules than in the arteries. Much of the endocytic activity in these

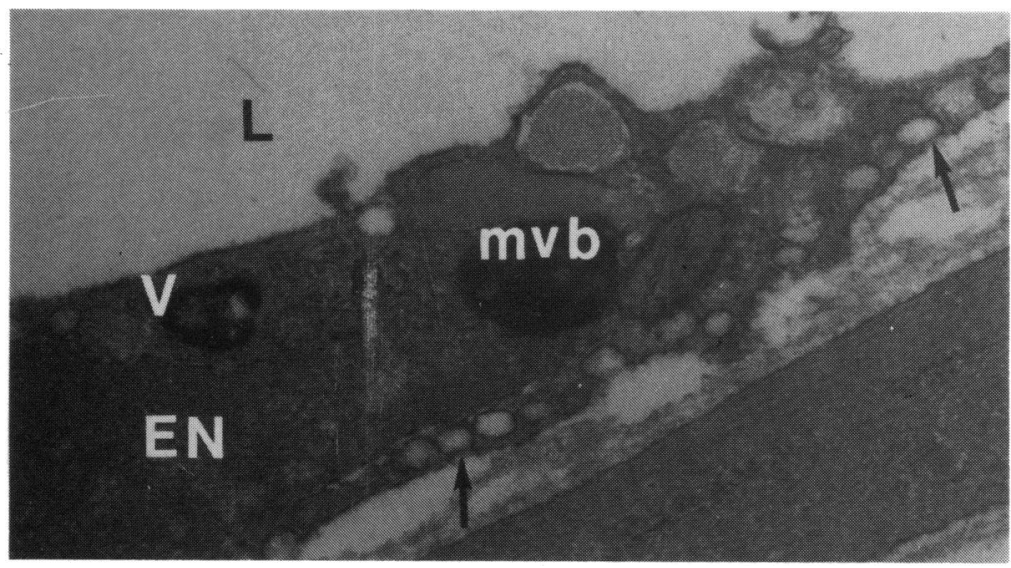

Fig. 3 Choroidal vein (rat): perfusion fixation. Endothelial cell shows peroxidase reaction product within an endocytic vacuole (V) and a multivesicular body (mvb). Note stomatal diaphragms of plasmalemmal caveolae (arrows). Endothelial cell nucleus (EN). $(\times 45000)$. 


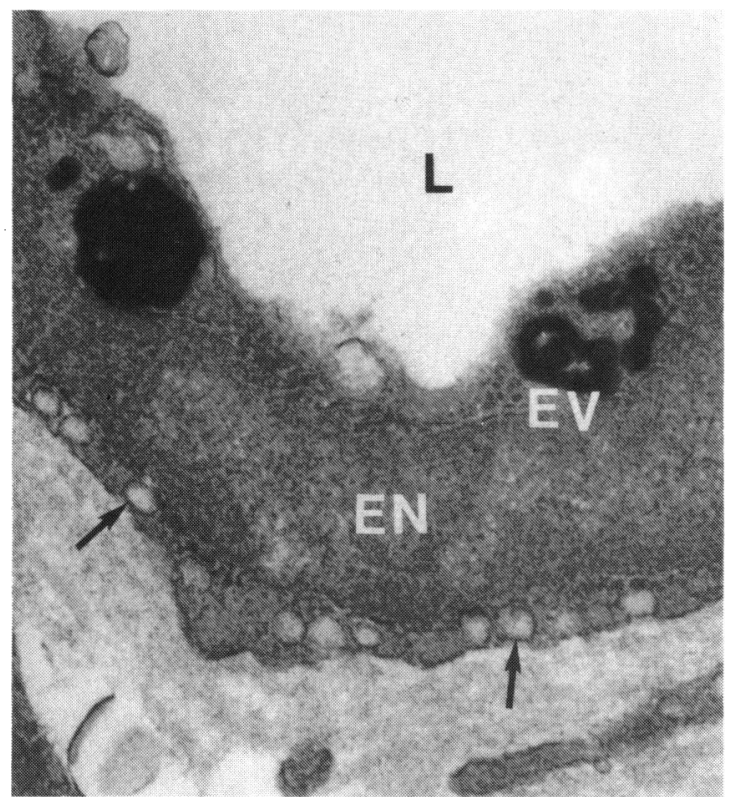

Fig. 4 Choroidal vein (rat): perfusion fixation. Peroxidase reaction product in endocytic vacuoles and dense bodies of venous endothelial cell. One profile suggests collapse and folding of the original vacuole (EV). Note stomatal diaphragms of plasmalemmal caveolae (arrows).

Endothelial nucleus (EN), lumen (L). $(\times 45000)$.

vessels occurred in the perinuclear cytoplasm (Fig. 3). Some profiles of endocytic vacuoles suggested collapse and folding of the limiting membrane (Fig. 4).

All the elements of the endocytic system described in the choroidal arteries and veins could be identified in the non-fenestrated regions of the choriocapillary endothelial cells. However, the highly attenuated 'stretched out' nature of these cells made peroxidase labelled bodies seem sparse when compared with the more bulbous endothelium of the arteries and veins.

Peroxidase reaction product in the endocytic vacuoles was usually localised to a regular layer 20-30 nm thick on the inner surface of the limiting membrane, leaving an electron transparent core (Fig. 5). Although it was impossible to observe macropinocytosis in this model (perfusion fixation removes incompletely internalised tracer), the pseudopodia associated with the phenomenon were often seen at the luminal plasma membrane (Fig. 5).

The clarification of the extracellular space by perfusion fixation permitted a better evaluation of the plasmalemmal caveolae of the endothelium and those of the neighbouring smooth muscle cells. A large population of the caveolae had their stomata closed by thin flocculent diaphragms. Caveolae without diaphragms were usually located on the luminal plasmalemma. Diaphragms also covered the caveolae of the smooth muscle cells of the arteries and the pericytes of the veins and capillaries. All such caveolae were free of peroxidase following perfusion fixation (Fig. 6). Despite the vast arrays of caveolae present along the plasma membranes of the smooth muscle and pericyte cells no internalised tracer was detected in their cytoplasm.

Peroxidase was also taken up by many choroidal fibroblasts and occasional wandering macrophages. The endocytic vacuoles in both these cell types were almost identical to those encountered in the vascular endothelium, having an electron transparent core and $20-30 \mathrm{~nm}$ layer of peroxidase stained material on the internal aspect of the limiting membrane.
Fig. 5 Choroidal vein (rat): perfusion fixation. Peroxidase reaction product within endocytic vacuole of endothelial cell $(\mathrm{E})$ is localised to a 20-30 nm layer on the inner surface of the limiting membrane (white arrow). Lumen (L), pseudopodia (black arrow). $(\times 45000)$.

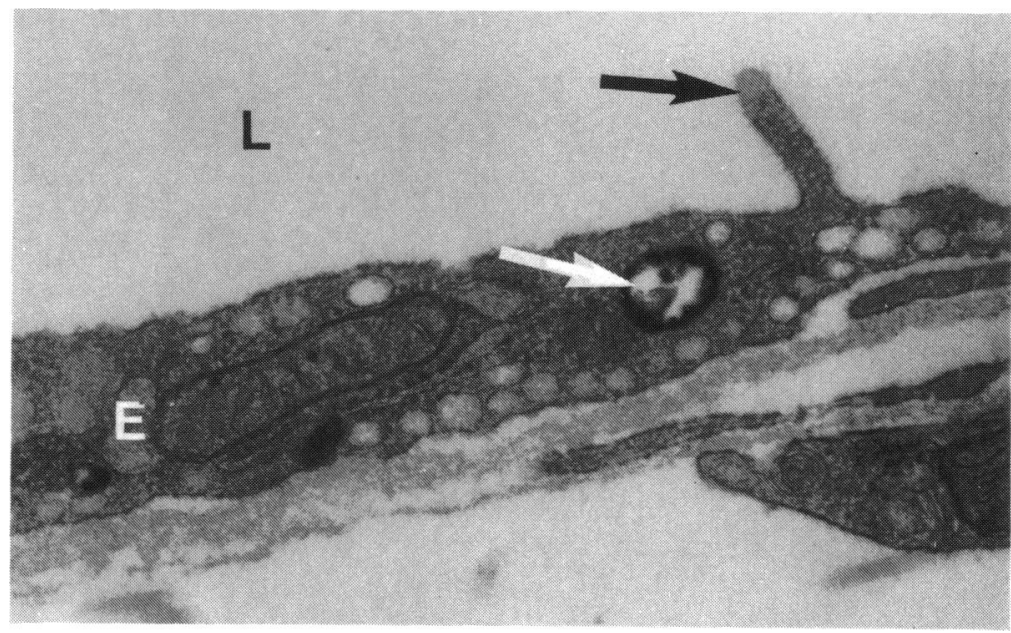




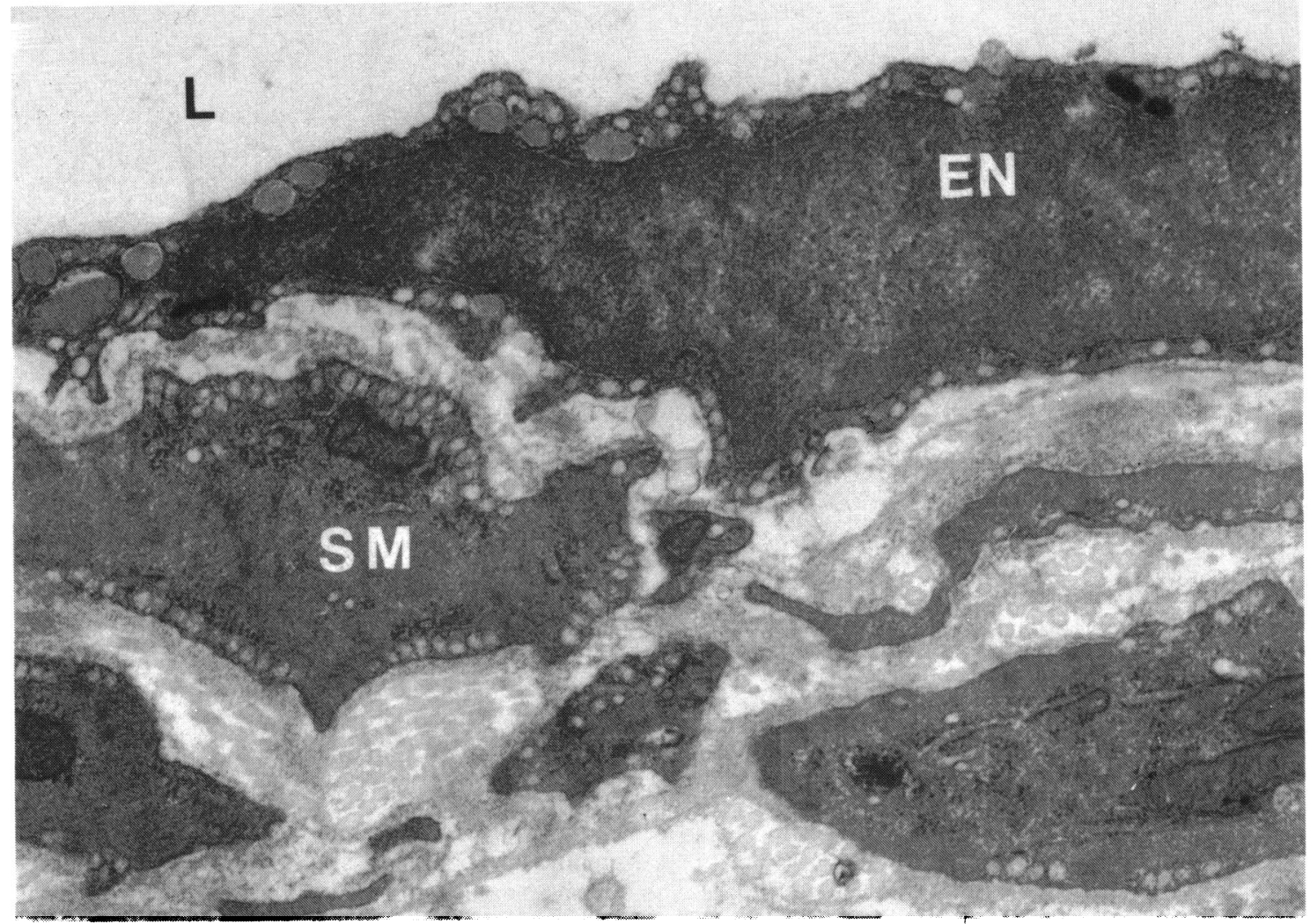

Fig. 6 Large choroidal vein (rat): perfusion fixation. The plasmalemmal caveolae of the endothelium and sarcolemmal caveolae of the smooth muscle cells $(\mathrm{SM})$ are free of peroxidase after perfusion fixation. Endothelial nucleus $(\mathrm{EN}) .(\times 23730)$.

ENDOCYTOSIS OF HORSERADISH PEROXIDASE BY THE VASCULAR CELLS OF THE RETINA

The endocytosis of circulating peroxidase by vascular endothelial cells in the retina is somewhat different from the choroid in that (because of the blood retinal barrier) only the luminal plasma membrane is exposed to the tracer. Immersion fixed specimens of retinal blood vessels exposed to intravascular peroxidase for $15 \mathrm{~min}$ revealed peroxidase reaction product throughout the fixed intraluminal plasma proteins (Fig. 7). There was also uniform staining of a 20 $30 \mathrm{~nm}$ thick layer on the luminal surface of the endothelial cells. This layer covered the entire luminal surface, including the inside of the plasmalemmal caveolae and associated 'vesicles' (Fig. 7). An identical layer of peroxidase reaction product lined the internal surfaces of endocytic vacuoles (300-400 nm diameter) (Fig. 7) and vesicles (100$130 \mathrm{~nm}$ diameter) (Fig. 8), leaving electron transparent core regions. On several occasions a similar layer $(20-30 \mathrm{~nm})$ of peroxidase reaction product was found within cisternae of the Golgi apparatus (Fig. 9). However, in such instances staining was confined to the trans end of the stack. Peroxidase was also found in large lysosome-like structures and in multivesicular bodies which were generally labelled after 15 minutes exposure to the tracer. In multivesicular bodies where good localisation had been achieved the enclosed vesicles were seen to be free of peroxidase, which was confined to the matrix of the body (Fig. 10).

Perfusion fixed specimens showed no adsorbed peroxidase at the luminal plasmalemma of the retinal endothelial cells (Fig. 11). Furthermore, only a tiny proportion of the apparently labelled 'vesicles' observed in immersion fixed specimens were found to be truly internalised. The bulk of internalised tracer was found to reside in the large endocytic vacuoles described above. All the vessels examined in this study showed an overwhelming preponderance of plasmalemmal caveolae at the abluminal cell surface as compared to the luminal plasmalemma (Fig. 11).

RUTHENIUM RED STAINING OF THE LUMINAL CELL COAT OF THE RETINAL ENDOTHELIUM

Ruthenium red/glutaraldehyde primary fixation and 


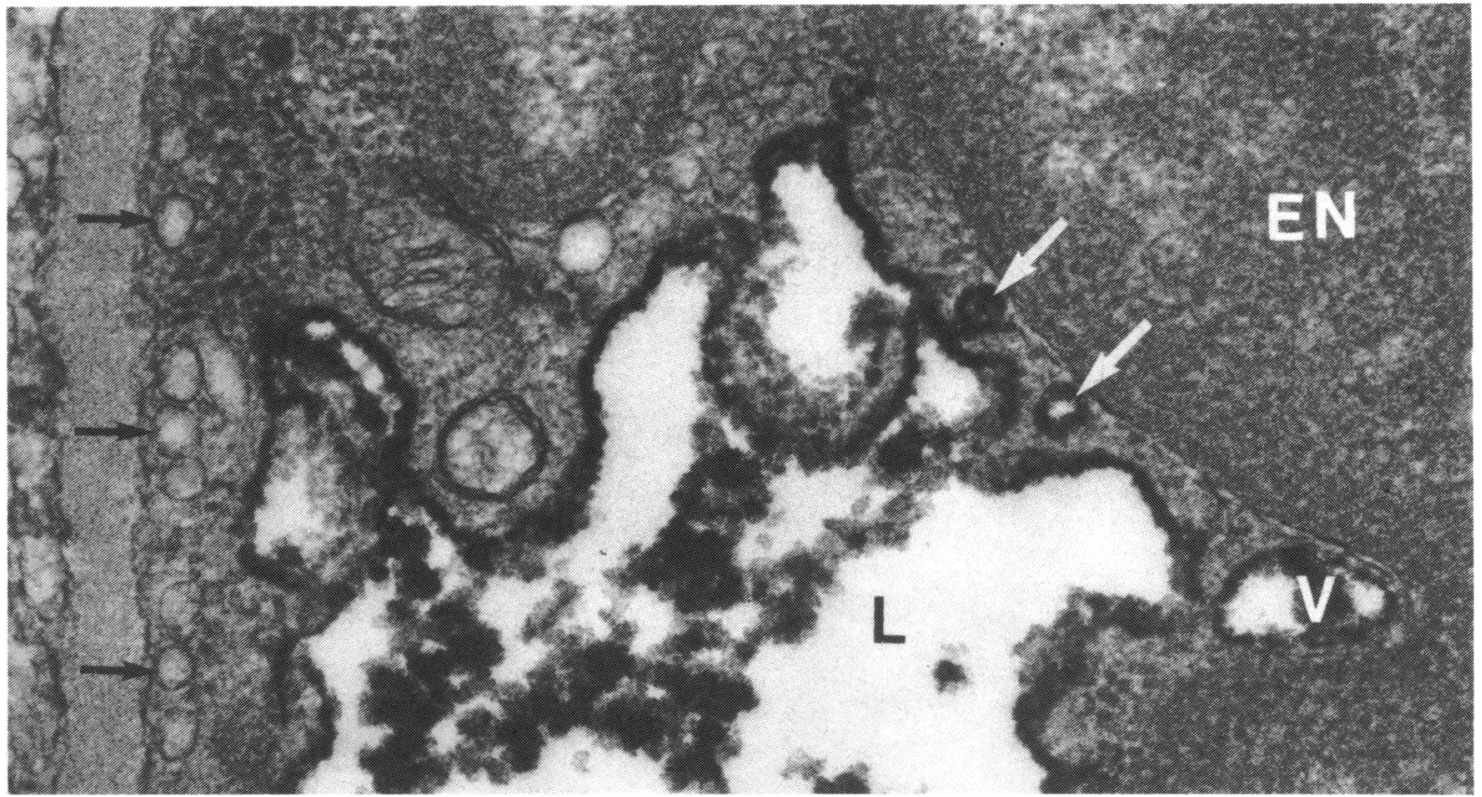

Fig. 7 Retinal capillary (rat): immersion fixation. Peroxidase reaction product stains a 20-30 nm layer on the luminal cell surface. A similar layer coats the inside of an endocytic vacuole (V) and adjacent 'vesicles' (white arrows). Lumen (L), endothelial cell nucleus (EN). Note abluminal plasmalemmal caveolae (black arrows). $(\times 56450)$.

ruthenium red/osmium tetroxide staining produced a highly electron opaque product within the luminal surface coat of the retinal endothelial cells. The cell surface was completely invested by this coat, which was in intimate contact with the outer leaflet of the plasma membrane. The stained layer, which was 20-30 nm deep, lined the inside of the plasmalemmal caveolae (Fig. 12) and adjacent 'vesicles' (Fig. 13), leaving an electron transparent core region. However, in all instances where 'vesicle' images were encountered in these preparations the adjacent plasma membrane was obviously in oblique section (Fig. 13).

\section{Discussion}

\section{CHOROID}

The endothelial fenestrations of the choriocapillaris afford a small protein such as horseradish peroxidase (MW 43000 , Einstein-Stokes radius $3 \mathrm{~nm})^{\mathrm{x}}$ unlimited access to the extracellular space of the choroid, thus presenting the protein to both luminal and abluminal aspects of the endothelium within a short period of time. In the choroidal arteries this effect served to demonstrate the presence of tight junctions between the endothelial cells and to outline 'privileged areas' of the intercellular clefts bounded by them. Examination of these privileged zones revealed plasmalemmal caveolae on the lateral plasma membrane which also remained free of peroxidase. Such caveolae have been associated with macromolecular transport ${ }^{4}$ " 1 yet occur on surfaces from which circulating proteins at least as large as horseradish peroxidase are excluded.

Another consequence of simultaneously filling the vascular lumen and extracellular space with tracer was that almost every pit and vesicle on the luminal and abluminal plasma membranes appeared labelled, together with the sarcolemmal caveolae of the smooth muscle cells and pericytes. This picture would have proved misleading had identical perfusion fixed choroid not been available. Following a short buffer 'washout' of the extracellular space and perfusion fixation the great majority of the labelled endothelial 'vesicles' had to be reconsidered as plasmalemmal caveolae whose stomata lay outside the plane of section.

The change in the caveolae of the smooth muscle cells was even more dramatic after perfusion fixation, all pits and vesicles being completely empty, with no genuinely internalised peroxidase. This finding was predictable, as Gabella" has shown that, in smooth muscle cells, caveolae have a role in surface area modulation but not in endocytosis. In smooth muscle cells it is likely that caveolae facilitate the transport of calcium ions across the sarcolemma. ${ }^{1213}$

The caveolae of the smooth muscle cells were indistinguishable from those of the endothelium, many examples of each having their stomata covered 


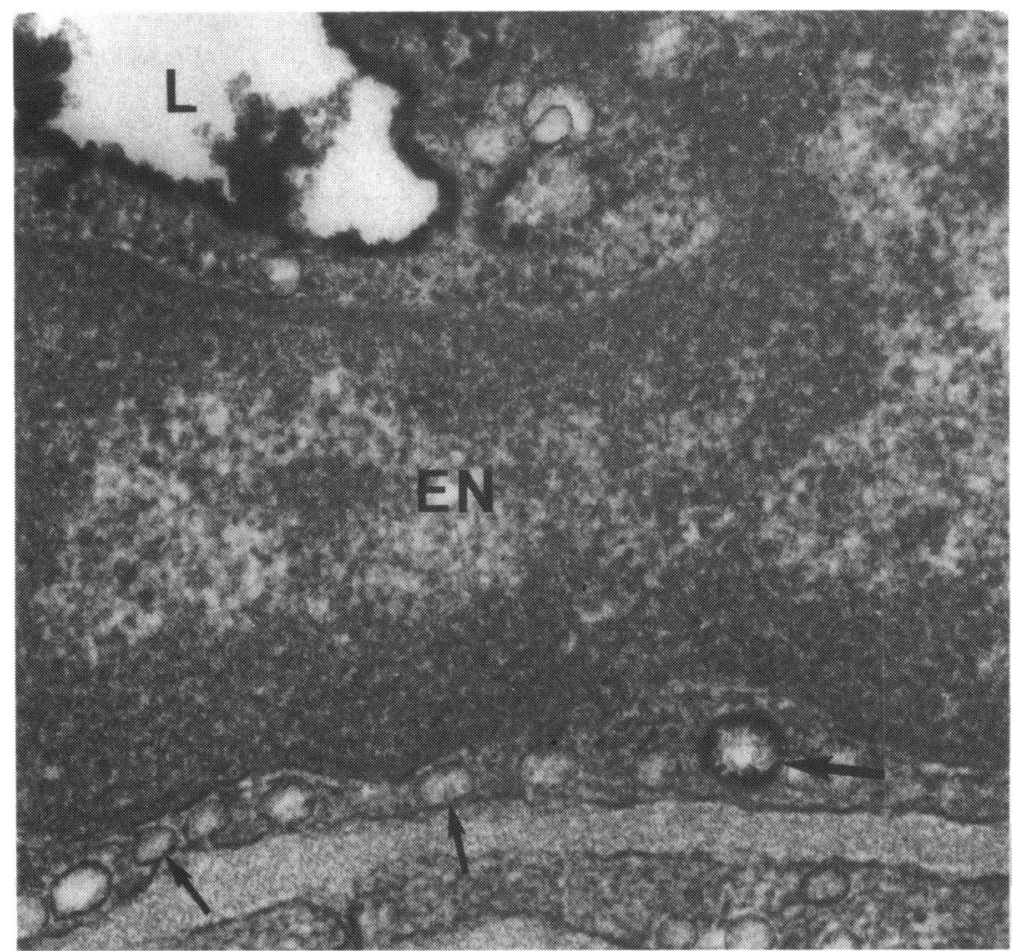

Fig. 8 Retinal capillary (rat): immersion fixation. Peroxidase reaction product coats luminal cell surface and a 20-30 nm layer on the internal surface of an endocytic vesicle at the abluminal plasmalemma. Note the endocytic vesicle (large arrow) is considerably larger than the plasmalemmal caveolae adjacent to it (small arrows). Endothelial cell nucleus $(\mathrm{EN})$, lumen $(\mathrm{L}) .(\times 60000)$. 
Fig. 10 Retinal capillary (rat): immersion fixation. Peroxidase reaction product is present in the matrix of a multivesicular body (mvb) but not in the enclosed vesicles (arrow). Endothelial cell nucleus $(\mathrm{EN})$, lumen $(\mathrm{L})$. $(\times 60000)$.

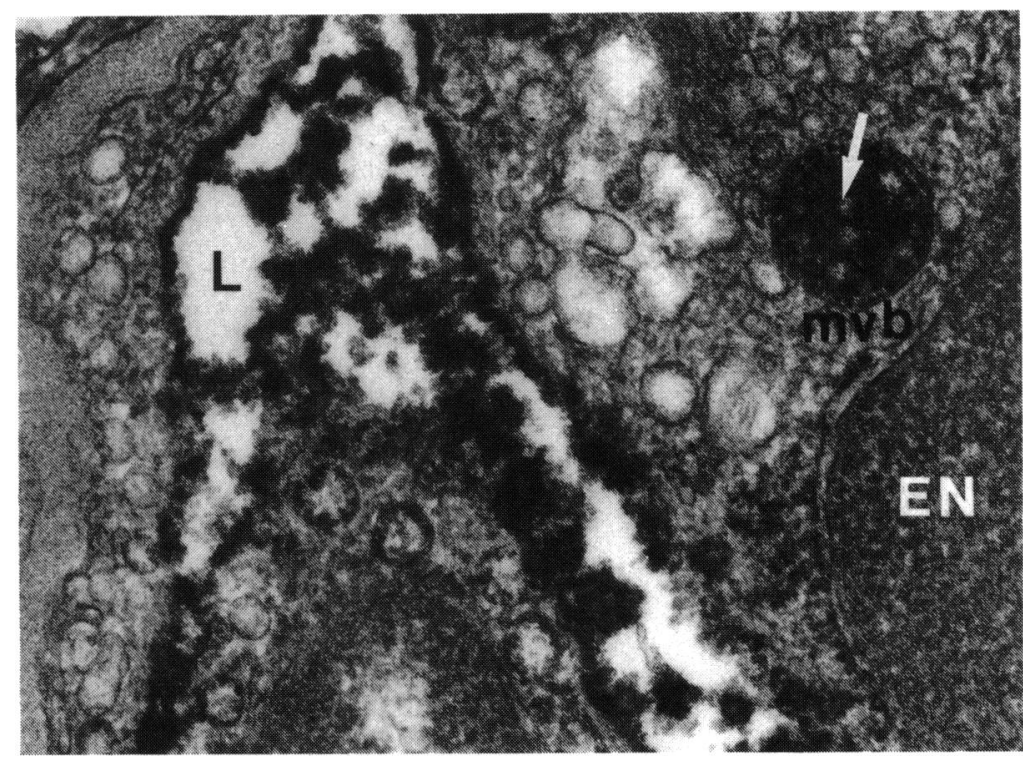

The concept of vesicular transport in vascular endothelia has recently been seriously challenged by Frøkjaer-Jensen ${ }^{17}$ and Bundgaard et al. ${ }^{1 \times 19}$ who, in studies of $14-15 \mathrm{~nm}$ serial sections, concluded that the plasmalemmal vesicles of vascular endothelia are units of an extensive system of racemose invaginations of the plasmalemma and are seldom if ever found free in the cytoplasm. These findings prompted Crone $^{20}$ to suggest that the use of the term 'micropinocytosis' be discontinued. Therefore it seems likely that the plasmalemmal caveolae of vascular endothelial cells may have an analogous role to those in smooth muscle cells. The expansion of the cell surface provided by such structures would provide more usable membrane for discrete functions such as simple or facilitated diffusion or active transport. Such a role for endothelial caveolae is supported by studies indicating the presence of enzymes associated with active transport within them. ${ }^{21}$

The endocytosis of horseradish peroxidase in the choroidal endothelia, whether in small vesicles or large vacuoles, appeared to be a function of plasma membrane recycling. Tracer was invariably internalised after adsorption to a $20-30 \mathrm{~nm}$ thick layer on the external surface of the luminal plasma membrane. This layer, which was thought to represent the luminal cell coat or glycocalyx of the endothelium,,$^{22}$ persisted until the form of the original vacuoles was lost following fusion with multivesicular bodies or lysosomes.

RETINA

The peroxidase labelling characteristics of the retinal 


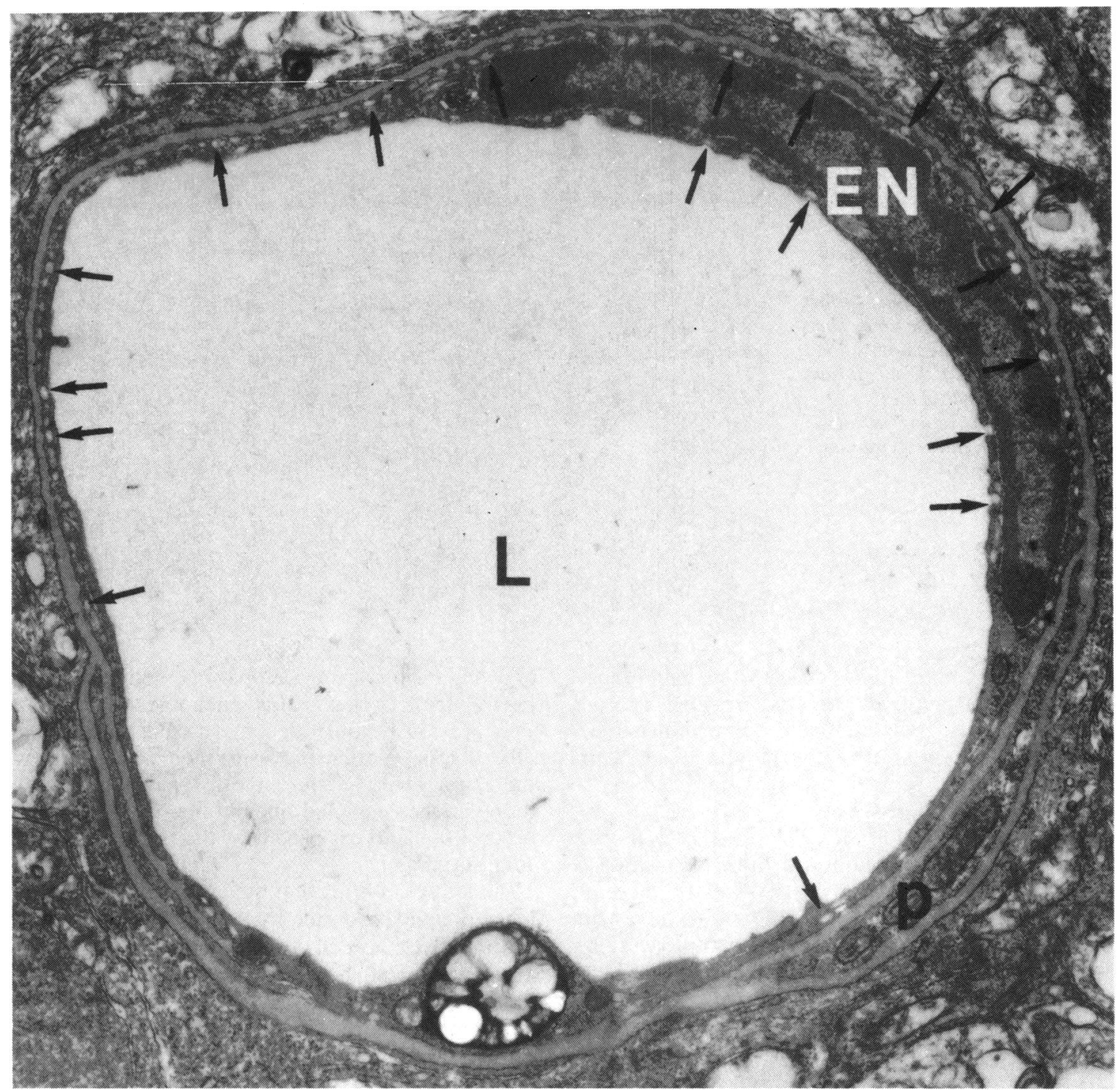

Fig. 11 Retinal venule (rat): perfusion fixation. Peroxidase reaction product stains a large lysosome-like inclusion. The plasmalemmal caveolae and associated vesicles appear empty (arrows). Note preponderance of abluminal over luminal caveolae. Endothelial cell nucleus $(\mathrm{EN})$, lumen $(\mathrm{L})$, pericyte process $(\mathrm{P}) .(\times 19100)$.

vascular endothelium differed only quantitatively from the choroidal vessels, showing a similar distribution between small vesicles and large vacuoles. The large endocytic vacuoles were thought to arise through simple folding and fusion of the luminal plasmalemma and to represent a recycling phenomenon of the plasma membrane. The few unambiguously labelled vesicles which were found free in the cytoplasm were of an order of magnitude (100-130 $\mathrm{nm}$ ) which excluded them as derivatives of the $80 \mathrm{~nm}$ diameter plasmalemmal caveolae but suggested that they may have arisen from clathrin coated pits.
A $20-30 \mathrm{~nm}$ layer of peroxidase stained material covered the entire luminal surface of immersion fixed retinal endothelial cells and lined the interior of the endocytic vacuoles. This layer was assumed to be the peroxidase stained cell coat or glycocalyx of the luminal plasma membrane and was identical to that of choroidal endothelial cells. The bulk of internalised plasma membrane and its peroxidase labelled coat material was incorporated into either heterophagic vacuoles or multivesicular bodies. The multivesicular bodies or endosomes ${ }^{23}$ probably became labelled through incorporation of vesicles derived 
Fig. 12 Retinal venular endothelial cell (rat): perfusion fixation plus ruthenium red/osmium tetroxide staining. Positive staining is confined to a 20-30 nm layer on the outer surface of the luminal plasmalemma. The stained layer is in close apposition to the outer leaflet of the membrane and coats the inside of the plasmalemmal caveolae (arrows). Lumen (L), basement membrane (BM). $(\times 110000)$.

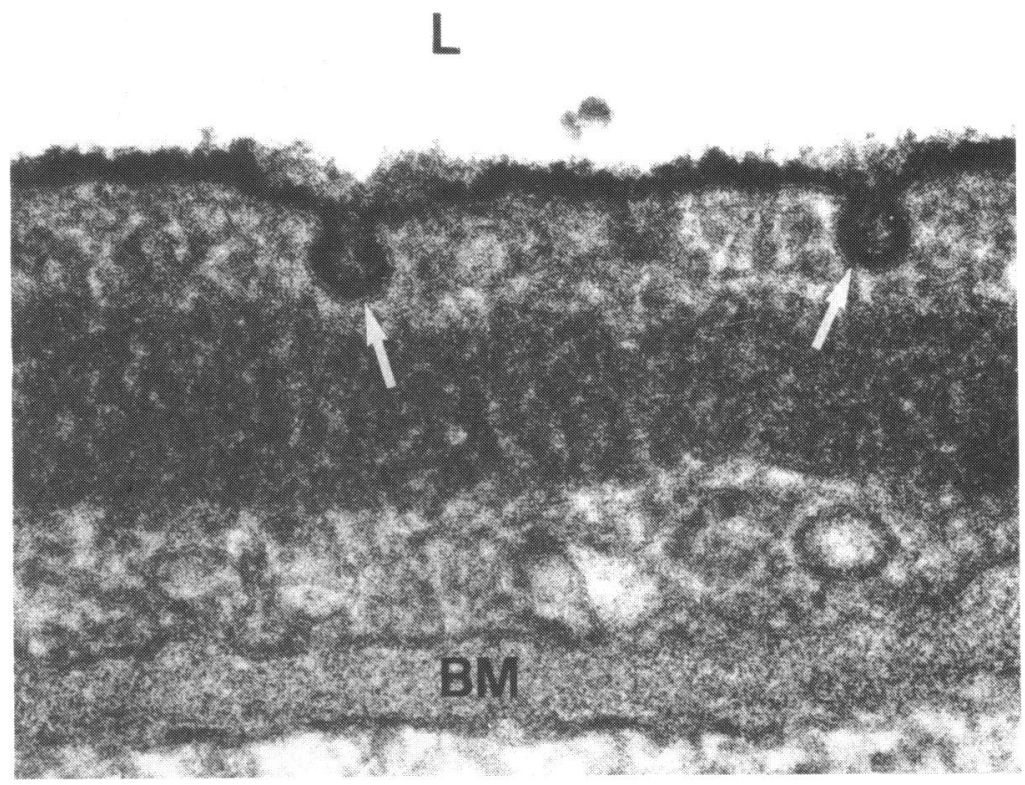

following fusion of recycled plasma membrane with trans-Golgi cisternae. This phenomenon has not been previously illustrated in vascular endothelial cells but is in accord with plasma membrane retrieval studies on several different cell types. ${ }^{2+27}$ In these studies tracer labelled membrane from the cell surface appeared exclusively at the trans end of the Golgi stack.

This study confirms that the endocytosis of horseradish peroxidase occurs by virtue of its association with the glycocalyx of recycled plasma membrane. Most commercial horseradish peroxidase contains several cationic isoenzymes and as such may show some non-specific binding to the anionic surface coat
Fig. 13 Retinal venular endothelial cell (rat): perfusion fixation plus ruthenium red/osmium tetroxide staining. Positive staining is present in the surface coat of the luminal plasma membrane and the internal aspect of the plasmalemmal caveolae. An apparent 'vesicle' (V) shows positive staining, but the adjacent plasma membrane is obviously in oblique section (arrow). Lumen (L). $(\times 80000)$. 
or glycocalyx present around most cells. ${ }^{22}$ This coat is rich in polyanions, which give it a net negative charge and render it stainable with cationic dyes such as ruthenium red. The glycocalyx is indistinct in conventional electron microscopic preparations, though it may be demonstrated indirectly by adsorption of a demonstrable substrate, such as horseradish peroxidase..$^{2 x}$ In the present context horseradish peroxidase may be described as a general marker of endocytosis, for, although it is itself internalised by a nonconcentrative process, if present in the extracellular medium it may be non-specifically adsorbed to the glycocalyx covering clathrin coated pits $^{29}$ involved in highly concentrative receptor mediated endocytosis. ${ }^{23}$

A luxuriant glycocalyx has been demonstrated on the luminal surface of vascular endothelial cells in other tissues. ${ }^{3131}$ That the $20-30 \mathrm{~nm}$ peroxidase adsorption zone observed in the present study was coincident with the luminal surface coat of the retinal endothelium was confirmed by direct staining with ruthenium red. The regular $20-30 \mathrm{~nm}$ thick layer revealed by ruthenium red on the luminal surface of the retinal endothelium proved identical both in thickness and distribution to the peroxidase adsorption zone observed above. As the same layer of stained material seen on the plasmalemma proper was found to coat the caveolae, oblique sections through such caveolae produced images identical to the peroxidase labelled vesicles described abovethat is, a $20-30 \mathrm{~nm}$ electron opaque layer tightly apposed to the limiting membrane, leaving an electron transparent core region.

As macropinocytosis is common at the luminal plasma membrane of retinal and choroidal vascular endothelial cells, it seems likely that this system corresponds to the major pathway for plasma membrane recycling in such cells and that the uptake of extracellular protein by the system is fortuitous. As electron micrographs of these vacuoles show that demonstrable tracers are confined to a thin layer on the internal surface of the limiting membrane while the rest of the vacuole appears artificially empty, it is proposed that macropinocytosis occurs through simple folding and fusion of plasma membrane without any significant attempt to imbibe fluid from the extracellular medium. Furthermore, in comparison with receptor mediated endocytosis ${ }^{23}$ the uptake of extracellular fluid, with its low concentration of nutrient and contamination by metabolic wastes, seems inefficient, especially when coupled to the gross membrane recycling entailed in the process. The endocytosis of horseradish peroxidase, by virtue of its association with the cell coat or glycocalyx, defines it as a general marker of plasma membrane retrieval rather than an indicator of fluid uptake.

\section{References}

1 Shiose Y. Electron microscopic studies on blood retinal and blood aqueous barriers. Jpn J Ophthalmol 1970; 14: 73-87.

2 Peyman GA, Spitznas M, Straatsma BR. Pcroxidase diffusion in the normal and photocoagulated retina. Invest Ophthalmol Vis Sci 1971; 10: 181-9.

3 Shakib M, Rutkowski P, Wisc GN. Fluorescein angiography and the retinal pigment epithelium. Am J Ophthalmol 1972; 74: 206-18.

4 Bernstein MH, Hollenberg MJ. Fine structure of the choriocapillaris and retinal capillaries. Invest Ophthalmol Vis Sci 1965; 4: 1016-25.

5 Williams TH, Jew JY. An improved method of perfusion fixation of neural tissues for electron microscopy. Tissue Cell 1975; 7: 407-18.

6 Malmgren L, Olsson Y. A sensitive method for histochemical demonstration of horseradish peroxidase in neurones following retrograde axonal transport. Brain Res 1978; 148: 279-94.

7 Luft JH. Ruthenium red and violet. I Chemistry, purification, methods for use for electron microscopy and mechanism of action. Anat Res 1971; 171: 347-68.

8 Farquhar MG. The primary glomerular filtration barrier, basement membrane or epithelial slits. Kidney Int 1975; 8: 197-211.

9 Simionescu N, Simionescu M, Palade GE. Permeability of muscle capillaries to exogenous myoglobin. J Cell Biol 1973; 57: 424-52.

10 Simionescu N, Simionescu M, Palade GE. Permeability of muscle capillaries to small heme-peptides. J Cell Biol 1975; 64: 586-607.

11 Gabella G. I Cellular structures and electro-physiological behaviour. Fine structure of smooth muscle. Philos Trans $R$ Soc Lond (Biol) 1973; 265: 7-16.

12 Popescu LM, Diculescu I, Zelek U, Ionescu N. Ultrastructural distribution of calcium in smooth muscle cells of guinca-pig taenia coli. Cell Tissue Res 1974; 154: 357-78.

13 Popescu LM. Conceptual model of the excitation-contraction coupling in smooth muscle: the possible role of surface microvesicles. Studia Biophysica (Berlin) 1974; 44: 141-53.

14 Bruns RR, Palade GE. Studies on blood capillaries. I General organization of blood capillaries in muscle. J Cell Biol 1968; 37: 244-76.

15 Bruns RR, Palade GE. Studies on blood capillaries. II Transport of ferritin molecules across the wall of muscle capillaries. $J$ Cell Biol 1968; 37: 277-99.

16 Crowther RA, Finch JT, Pearse BMF. On the structure of coated vesicles. J Mol Biol 1976; 103: 785-98.

17 Frøkjaer-Jensen J. Three-dimensional organization of plasmalemmal vesicles in endothelial cells. An analysis by serial sectioning of frog mesenteric capillaries. J Ultrastruct Res 1980; 73: 9-20.

18 Bundgaard $M$, Hagman $P$, Crone $C$. The three-dimensional organization of plasmalemmal vesicular profiles in the endothelium of rat heart capillaries. Microvasc Res 1983; 25: 358-68.

19 Bundgaard M. Vesicular transport in capillary endothelium: Does it occur? Fed Proc 1983; 42: 2425-30.

20 Crone C. The function of capillaries. Recent Adv Physiol 1984; 10: $125-62$.

21 Marchesi VT, Barrnett RJ. The demonstration of enzymatic activity in pinocytotic vesicles of blood capillaries with the electron microscope. J Cell Biol 1963; 17: 547-56.

$22 \mathrm{Luft} \mathrm{JH}$. The structure and properties of the cell surface coat. Int Rev Cytol 1976; 45: 291-382.

23 Brown MS, Anderson RGW, Goldstein JL. Recycling receptors: the round-trip itinerary of migrant membrane proteins. Cell 1983; 32: 663-7.

24 Pelletier G. Secretion and uptake by rat adenohypophyseal cells. J Ultrastruct Res 1973; 43: 445-59. 
25 Herzog V, Farquhar MG. Luminal membrane retrieved after exocytosis reaches most Golgi cisternae in secretory cells. Proc Natl Acad Sci USA 1977; 74: 5073-7.

26 Gonatas NK, Kim SU, Stuiber A, Avrameas S. Internalization of lectins in neuronal GERL. J Cell Biol 1977; 73: 1-13.

27 Farquhar MG. Recovery of surface membrane in anterior pituitary cells. J Cell Biol 1978; 77: R35-R42.

28 Behnke O. Electron microscopical observations on the surface coating of human blood platelets. J Ultrastruct Res 1968; 24: 51-69.
29 Zacks SI, Saito A. Uptake of horseradish peroxidase by coated vesicles in mouse neuromuscular junctions. $J$ Histochem Cytochem 1969; 17: 161-71.

30 Luft JH. Fine structure of the capillary and endocapillary layer as revealed by ruthenium red. Fed Proc 1966; 25: 1773-83.

31 Latta H, Johnston WH, Stanley TM. Sialoglycoproteins and filtration barriers in the glomerular capillary wall. J Ultrastruct Res 1975; 51: 354-76.

Accepted for publication 19 September 1985. 